\title{
13
}

\section{Information technology and the management of Victorian schools - providing flexibility or enabling better central control?}

\author{
Arthur Tatnall \\ Department of Business Computing, Victoria University of Technology, Melbourne, Australia
}

\begin{abstract}
:
Considerable use is now made of information technology in the management of Victorian Schools due partly to the early efforts of individual teachers, but more to Education Ministry central initiatives. This paper traces the use of computers in school management and the issues raised. One such issue is the feeling amongst a number of educators that IT is being used to force schools to adopt centrally determined administrative procedures, rather than to provide flexible structures to assist them to manage themselves. Planned future directions for school education, especially the 'Schools of the Future' project, make the increased use of IT essential in managing schools. What computer-based management systems are currently available, and how schools make use of these systems is demonstrated in case studies. A major problem identified is the lack of adequate available in-service training.
\end{abstract}

Keyword Codes: K.3.1; K.4.3; H.4.0

Keywords: Computer Uses in Education; Organisational Impacts; Information Systems applications.

\section{INTRODUCTION}

In the early 1980s a major study of the possible uses of computers in Australian schools by the Commonwealth Schools Commission identified important administrative applications including school accounts, stock records and student records. It saw these, however, as distinct from the curriculum use of computers in that "access to them is generally restricted to the school executive and administrative staff". [1]

In Victorian schools there has always been tension between those educators whose main interest is to use computers in the classroom, and those who are more concerned in using them to assist with management functions. Whilst both functions have always been recognised as important, over the years each group has seen what they were doing as the more important, and been a little suspicious of the other. The Schools Commission report followed by the setting up of separate Computer Education and Administrative Computing units by the Victorian Ministry of Education in the mid-1980s did nothing to reduce this problem.

\subsection{Structure of the Victorian School System}

Government schools in Victoria enrol only about $65 \%$ of Victorian students, the remainder being catered for by the independent schools. Until the mid-1980s the Victorian 
State School System consisted of three separate divisions: Primary Schools (P-6), Secondary Schools (7-12) and Technical Schools (7-11). These divisions operated almost as separate school systems, while independent schools had little contact with state schools.

\subsection{Early use of computers in the management of Victorian schools}

In order to understand why current systems are as they are, it is instructive to examine how the use of computer-based management systems evolved and the political environment in which this has occurred. In the early 1970s the first computers began to appear in Victorian schools. These early machines, often loaned or leased PDP-8s and the like, usually entered the school's mathematics department and were used solely for programming thus having little overall impact on the educational program or management of these schools. In this period however, a number of the larger non-government schools purchased their own minicomputers to use in administrative applications such as payroll, accounts and student enrolments [2]. Later the use of these minicomputers was extended to such management applications as student/class allocation, timetabling and student reports, a pattern that is still followed today.

In Government schools much less administrative work needed to be done 'on-site' as the Education Department's central bureaucracy handled the management of such things as teachers' salaries, building contracts and school cleaning. In the mid to late-1970s a number of State secondary schools began making use of minicomputers located in nearby universities for tasks including student/class allocation and the marking of tests. When microcomputers appeared in the late 1970 s and early 1980 s, a number of management applications, typically written by teachers themselves, also began to emerge. These included computer programs to manage the results of school sports meetings, simple financial packages, student records databases and programs to assist in timetabling [3]. The availability of microcomputers also provided a stimulus for the adoption of computerised school library systems.

\subsection{Victorian Education Ministry administrative computing initiatives in the 1980s}

In the early 1980s a newly elected Victorian Government discovered that it was impossible to get consistent financial data from its governments departments, as each had its own accounting system [4]. This meant that the government was unable to draw up a balance sheet for the State of Victoria as a whole, and as a consequence it quickly decided to set up accounting standards that would be used by all government departments, and to institute a centralised accounting system.

Furthermore, the Auditor General had been particularly critical of the Ministry of Education as only about $40 \%$ of its schools had been sending in detailed statements of expenditure. The task of sending field auditors to all of these schools would have been enormous, so the solution decided upon was to supply each school with an administrative computer system and specific accounting software in order to make them more accountable [4]. The Ministry of Education considered itself big enough not to need to outsource this task and, in 1985, set up the Schools Administrative Computing Unit (SACU) with the initial task of developing suitable accounting software.

John Birse, who was soon to become the co-ordinator of this unit, describes how its first job was to determine what language the software package should be written in. They chose Dataflex in the belief that this would simplify future program maintenance [4]. At a curriculum level at that time, most primary and secondary schools used Apple hardware and this presented problems in the development of administrative systems which would need to be 
similar to those used in business and hence be based on a CP/M or MS-DOS platform. The technical schools of the day used mainly CP/M equipment but this was right at the time that $\mathrm{CP} / \mathrm{M}$ was about to be replaced in most business applications by MS-DOS.

A double entry accounting system was then developed in Dataflex and trialed at a number of schools. In line with the aim of making schools more centrally accountable, this system imposed an unalterable chart of accounts, which while suitable for large secondary and technical schools was seen by small primary schools as unnecessarily complex. Birse suggests that "the system was definitely not set up to empower schools. It was fairly imposed, and from that point of view they got it wrong." [4]

To get things going, participating schools were each given an administrative computer (initially an IBM-AT) and the new accounting software. Installation and training were to be provided by SACU but, according to Birse, initially SACU just "dropped boxes on schools" and what training there was came later. SACU had only six consultants, three of whom were auditors and three with a school background, nowhere near enough to perform the enormous task required of them. The training of school administrative staff suffered accordingly, a problem that continues today.

\section{ADMINISTRATIVE COMPUTING SYSTEMS IN SCHOOLS}

Following the development of the Schools Accounting System (SAS), as it came to be known, SACU went on to develop a Student Records package as a step towards the currently available systems. There are now four different computer-based management systems in place in Victorian Government schools. These are known as SAS, CAAS, VASS and CASES.

\subsection{Schools Accounting System (SAS)}

This double entry accounting system is now installed in over 1400 schools. Extensions to the system allow it to accept input directly from a cash register, so facilitating the collection of money from students.

\subsection{Computer Aided Administrative System (CAAS)}

This is essentially a DBMS, complete with a set of pre-designed reports. It is currently installed in 1400 schools and is set up to hold student records and staff details.

\subsection{Victorian Certificate of Education Administrative Software System (VASS)}

In 1992, after several years of discussion and planning, a new year 11/12 course; the Victorian Certificate of Education (VCE) was introduced into Victorian schools. VCE students study 24 semester length units over their final two years at school, allowin much more choice than the previous Higher School Certificate (HSC). Assessment is als handled quite differently. Under the old HSC, assessment in most subjects consisted of an external examination, typically worth $50 \%$ of the marks, with school-assessed option material making up the remainder. The VCE, on the other hand, involves no external examinations, but a number of Common Assessment Tasks (CATs). Some of these CATs are externally set and marked while others are school assessed with some external moderation. This large component of school-based assessment requires schools to keep much more strict and comprehensive student records than before. 
To facilitate this record keeping, and the transfer of data to the Board of Studies (BOS), the Ministry of Education then provided each secondary school with a microcomputer, laser printer, modem and special VASS software. It also initiated a significant programme of in-service training for teachers acting as school VCE coordinators, to assist them to use the system. The VASS system is installed in 640 school locations, and is intended to provide both a school database of VCE details and result, and a mechanism for the transfer of data between the BOS and the schools. Data from the Board is typically sent via modem while school results are returned on floppy disk. The VASS system provides the following functions:

1. Student menu

- Student personal and Home Group details.

2. Teacher menu

- Details of VCE teachers.

3. VCE programs setup menu

- VCE units offered, teachers allocated, CAT dates, projected enrolments.

4. Student programs menu

- Students allocated to classes, student status enquiry and program summary, print class lists, print student CAT timetables.

5. Results menu

- Results input sheets, co-ordinator's record sheets, student CAT results, VCE student profiles, results enquiry, Home Group summary sheets, interim reports, end-of-unit reports, students-at-risk reports, create remote results disk.

6. Data transfer menu

- School to BOS data transfer: VCE projected enrolments, actual enrolments, initial assessments, unit completion, student profiles, school information. BOS to school data transfer: confirmation of enrolments, timelines. School to School data transfer: details of transferring students.

7. End of year procedures menu - Transfer of VASS data to CAAS, import teacher and student details from CAAS, student history, delete past student data, BOS unit descriptions, statistics on student enrolment, unit completion, CATs, results.

8. System maintenance menu - Backup, VASS defaults, upgrade, authorised users, passwords, query database, mail merge - mailing labels, student letters.

9. Student enquiries menu - Student summary or full details, student details by Form group, Home Group lists, population details.

\subsection{Computerised Administrative Systems Environment in Schools (CASES)}

The previously described systems are all function specific, and the Directorate of School Education (DSE) is now in the process of introducing a more integrated system that will eventually link the following components:

- School Finance (SAS)

- Student and Staff Administration (CAAS)

- Assets Management

- VCE Administration (VASS) 
The DSE describes the CASES development philosophy as placing "great emphasis on an integrated database management system. All school records should be part of an overall construct where a general information system comprising students, staff, assets, facilities and financial data is readily available to school-based personnel to assist in the administrative process."[5] Some of this linking is present in current versions of CASES while more is to be added later. CASES development is undertaken by the CASES Development Section (SACU's successor) in Dataflex 2.3. CASES is designed to operate in a Novell Netware LAN environment, and to be able to transfer data to Windows applications such as Microsoft Word. Telecom's Keylink facility, along with the Desklink package, is to be used for electronic data transfer between schools and the DSE.

CASES will provide the following sub-systems, not all of which are implemented in the current release:

1. Student administration.

2. Course selection and timetabling.

3. Academic administration.

4. Unit goals and student assessment.

5. Travel/transport and locations.

6. Personnel administration.

7. Census reporting \& end of semester/year.

8. Assets register.

9. System utilities and computer setup.

\subsection{Decision Support Capabilities}

Schools will, of course, be able to use some of the reports generated by SAS, CAAS, VASS or CASES to assist with management decision making, but none of these systems has been equipped with the models necessary to provide schools with proper educational decision support facilities.

\section{THE 'SCHOOLS OF THE FUTURE' PROJECT}

The Victorian Government is piloting a programme in which a number of selected schools will become, to a large degree, self managing. The schools involved in this pilot project are to be known as 'Schools of the Future'. The intention is to devolve much of the administration, formerly done centrally, to these self managing schools, which will mean that as well as student administration, assets management and finances, additional personnel tasks such as teacher absences and leave, as well as some payroll and other functions will devolve to the school level. The DSE suggests that successful implementation of the pilot schem requires the provision of appropriate information technology facilities and support at the school level. The pilot schools, depending on their size, are thus now being provided with several networked PCs, a CD-ROM drive, a modem, a laser printer and CASES software. The schools will be asked do much of their reporting to the DSE from CASES via modem, and use of this software will soon become essential.

An article in the DSE's Education News explains that "CASES is central to enabling Schools of the Future to perform functions associated with self management and for the operation of efficient school-based administrative systems." [6] It adds that CASES will be 
used "to link schools to an electronic Wide Area Network (WAN) whereby schools will be able to link to the corporate system to maintain and retrieve basic personnel data, payroll entitlements and disbursement data." [6] This link was still to be implemented in May 1994.

In a departure from past practice the computer equipment supplied to the Schools of the Future will be leased by the Victorian Government from a commercial supplier. After a period of three years it will be updated. In addition to the CASES software, schools will be provided with Windows for Workgroups, Microsoft Word and Microsoft Works. DSE licensing agreements mean that these schools will also be able to purchase other Microsoft software at substantially reduced prices.

It is planned to provide information on school policies, procedures and guidelines, as well as the CASES manuals themselves, in CD-ROM format. A package to be known as Information Utility for Schools (InformUS), and using special Australian developed ISYS text retrieval software, is currently being developed. In 1995 the Government intended to extend the Schools of the Future program to cover all state schools.

\section{HOW THE PACKAGES ARE BEING USED: A TALE OF TWO SCHOOLS}

\subsection{Viewbank College}

Viewbank College is a Melbourne secondary school recently formed by the merger of Rosanna East and Banyule High Schools. The new school has 793 students, 59 teaching staff and 5 ancillary staff, but is not a School of the Future. Both of the constituent schools had been using computers in curriculum and management applications for some time, but to different degrees and with different hardware.

Lois Maguire, the school bursar, has been involved in the use of computers in school management for some years, and notes that substantial efficiency improvements have resulted from the introduction of these systems. Viewbank uses the Schools Accounting System (SAS) in stand-alone mode for accounts receivable, accounts payable and to produce trial balances. The system is presently unable to depreciate or hold assets. The school intends soon to purchase a new cash register which will be linked directly into the system. It is envisaged that this will save considerable time when accepting money for excursions and bookshop sales. [7]

Viewbank also uses the Computer Aided Administration System (CAAS) to store data on school assets, student personal information, student subject information and student absences. The system is also capable of handling staff absences but this facility is not used by the school at present. Maguire notes that it is very time consuming to enter student data, taking up to four minutes per student. Part of the problem is that the pre-designed input forms contain many fields not required by the school, but which cannot be deleted. This system is also used in stand alone mode but the school is currently in the process of installing a network which will provide read-only access to this information to the Principal, Vice Principal and various Year Level Co-ordinators around the school. Although the student records system is considered to be quite useful, the school's general office also maintains a manually operated card system of student records, as retrieval of data from the computer-based system is thought to take too long. CAAS is not linked to the accounting system.

The school library uses a Dynix Library System for cataloguing and borrowing functions, but like CAAS this is not linked with other management systems. Similarly, the commercial package used to assist in the production of the school timetable is also function specific. 
The school library uses a Dynix Library System for cataloguing and borrowing functions, but like CAAS this is not linked with other management systems. Similarly, the commercial package used to assist in the production of the school timetable is also function specific.

In offering VCE studies, Viewbank College is obliged to make use of the VASS system [8] which is also function specific at present, accept that it is possible to import a list of students from the Student Records System. The VASS database comes, each year, from the Board of Studies with the table of subjects already entered so the school has only to enter appropriate codes for the subjects studied by each student, and to indicate which teachers will take each class. The prime purpose of this system is to facilitate the transfer of student results from the school to the Board of Studies, and so a floppy disk is posted to the Board every time student data changes. The school also has a modem link to the Board but at present this is used only to receive messages from the Board. Unfortunately however no paper is saved as the school has to make hard copies of all its electronic mail anyway! Originally it was thought that each subject teacher would enter their own student results into the VASS computer, but this was found to be impracticable and staff now give hand written lists of results to the VASS co-ordinator who enters them all in batch mode. Maguire believes that the VASS system is running quite smoothly now.

Maguire sees distinct advantages in the computerised systems, noting that in particular the annual school census is now easier to perform, assets are more controllable and expenses like insurance and cleaning costs easier to calculate. At present no data is sent via modem to the DSE but it is likely that soon such things as census data, school statistics and details of teacher absences will be sent direct.

\subsection{Eltham East Primary School}

Eltham East Primary School is a vibrant community of 650 students led by an energetic, newly appointed Principal. The school has 34.5 teachers and 1.5 administrative staff, and has recently been selected to participate in the 'Schools of the Future' programme. The school prides itself in fostering good community relations and on providing students and staff with a pleasant work environment. It is a progressive school and the School Charter states that "Each classroom has its own computer and particular attention is being paid to developing the use of this technology in classroom programs" [9].

Bill Schrank, Eltham East's Principal, confesses that he has only recently attained any degree of computer literacy but that now, in addition to the PC in his office, he also has a computer at home. As a School of the Future, Eltham East has recently received a file server, four network workstations, a laser printer and a modem from the DSE. When the equipment was delivered he and the office staff were given a 30 minute tutorial by the supplier. This is the only training any of them have yet received and there has been no instruction at all on the use of the network! The file server, laser printer and two of the 486SX computers have been located in the general office, with the others computers in the offices of the Principal and Vice Principal. The school is not currently using the modem but has purchased, from its own funds, a cash register which is linked to the accounting system. One of the office computers is used to run the Student Records package and Schools Accounting System, while the other is used for word processing.

The Principal uses the PC in his office to compose and type his own letters using Word for Windows. [10] His computer is linked to the other management systems but he does not make use of these yet. Schrank thought about the wisdom of spending time word processing 
his own letters, rather than having them typed by the secretary, but decided that doing so would not only be quicker, but would also give him much needed practice at using his computer. Only recently did he discover than in saving his work to his own hard disk no one else was able to access it across the network - this was not pointed out in the 30 minute introduction. Schrank told me that one of his office staff is booked in to attend a full day DSE professional development activity on the use of the administrative systems. He would have liked to send more staff but was unable because of limited available places and high demand. $\mathrm{He}$ is most critical of the DSE's provision of training in the use of the system. [10]

The fourth workstation in the Vice Principal's office will later also be used to access the Student Records system but is now used mainly for writing daily staff notices using Word for Windows. The school has a very full timetable and would like to make use of timetabling software, but has so far not been able to find anything suitable. The school library has an OASIS system, using pre-printed bar codes, for cataloguing and borrowing. Two library terminals provide student access to the catalogue (plus another in the library work room) and one terminal is used for loans. This system is not linked to the administrative system. In the staffroom there is a stand alone Apple Macintosh Plus with a laser printer for staff use in the preparation of teaching materials and student reports. An MS-DOS computer linked to the library system has also just been installed in the staffroom. But of course, a modern school does not use only computer technology, and Eltham East Primary also has two mobile phones, a fax machine, three photocopiers and a copy printer for staff and administrative use.

Bill Schrank sees many advantages in the use of the computer-based management systems - particularly when the school is shown how to use them properly. He has already made use of a report on parent occupations, provided by the Student Records System, to locate a parent to assist with concreting and another for a landscape gardening project. The computer-based assets list means that finding how many chairs a given classroom should have is now 'childs play'. He is looking forward to being able to produce the statistics for the midyear census using the computer system. This previously was a most onerous task. The on-line system, using the modem, is still to come, but soon this will be used for reporting staff illness and transmitting school statistics and census data to the DSE.

\section{IN-SERVICE EDUCATION OF SCHOOL PRINCIPALS AND OFFICE STAFF}

The importance of convincing school Principals of the advantages of using computers in school management should not be taken for granted. In the past Principals were usually former teachers who had little experience or knowledge of management. With new appointment procedures however, aspiring Principals need to acquire management skills and they often do so by enrolling in appropriate tertiary courses at the Graduate Certificate, Graduate Diploma or Masters level. For example Victoria University of Technology offers award and short courses in information resource management and the use of common microcomputer software packages to educational administrators.

It is clear, however, that the problem of training management, administrative and clerical staff in the specific use of CASES software has been underestimated by the Directorate of School Education. While training in the earlier introduced VASS system was quite comprehensive, this has not been true of CASES. Courses are offered in only a few of the DSE School Support Centres and there are insufficient available places in those courses which 
are offered to meet the immediate demand. The amount of system documentation supplied with the software is also quite daunting to educational administrators, with over 400 pages on VASS, 300 pages on SAS and 500 pages on CASES. Schools say that the quality of the documentation is not the problem, just its quantity. Without guidance, they find it hard to distinguish the forest from the trees or even to know where to begin.

Meanwhile, schools are left to muddle along as best they can. According to Bill Schrank, what they really need is a consultant to come to the school to assist them on-site. Such assistance is however not available and the only alternative is to phone the CASES hotline which apparently receives up to 2000 calls per day.

\section{ISSUES OF CENTRAL CONTROL}

From the time of the first SACU accounting package, some schools have questioned whether these systems were intended to assist or to control them. Whereas previously they were able to keep their own financial and student records in their own way, now they would have to use a common system provided by the Education Ministry. In a large centralised system such as this, keeping track of what schools are really doing is difficult and relies to a great extent on the willing co-operation of each school. While it would be very hard for any to argue against the improved efficiency the use of information technology has brought, there has nevertheless been an increasing feeling that 'Big Brother' was looking every more intently at what they are doing. The Education Ministry has done nothing to reduce this fear.

John Birse [4] describes development of these systems as being based on a "purely topdown philosophy" designed primarily to suit the Ministry. He is glad that early dreams of terminals in schools which would be linked to the central system have not been fulfilled, but notes that this could still happen in the future. Lois Maguire [7] says that little support was ever given to school bursars who were placed under pressure to learn the new systems or resign. She complains that "If you feel 'they' don't care you won't try new things." In 1989 an Education Ministry review [11] of administrative staff in Victorian schools recommended that in view of the implementation of new technology, increased training and access to consultancy services be made available to these people. Little seems to have been done, and the criticism that like any system which does not cater to the needs and anxieties of the people involved, this system will not reach its full potential, seems an accurate one.

\section{REFERENCES}

1. Commonwealth Schools Commission (1984); Teaching, Learning and Computers: 1984 Information Kit.

2. Graham, John (1990); Computers in Administration - where are we?, Computing in Education Group of Victoria 1990 conference, Melbourne. Published in proceedings: Back to the Future - Forward to the Past.

3. Olsen, P. (1993); The 'BROAD' database, First Australian Computing in Education Conference (ACEC'83), Melbourne. Published in proceedings Could you use a computer?

4. Birse, John (1994); Interview. 
5. Directorate of School Education (1993); Computerised Administrative Systems Environment in Schools - MS-DOS desktop computer hardware specifications.

6. Directorate of School Education (1994); CASES - information technology for Schools of the Future, in Education News, February 1994.

7. Maguire, Lois (1994); Interview.

8. Jensz, David (1994); Interview.

9. Eltham East Primary School (1993); School Charter: Eltham East Primary School 4897, 1994-1996.

10. Schrank, Bill (1994); Interview.

11. Crawford, J. (Ed) (1989); Review of Administrative Staff in Schools: Outline of issues, findings and recommendations of the review team, Ministry of Education, Melbourne. 